\title{
Impact of counselling on selecting a hormonal contraceptive method
}

\author{
Darshna M. Patel ${ }^{1}$, Vandita K. Salat ${ }^{1}$, Mahesh M. Patel ${ }^{2 *}$ \\ ${ }^{1}$ Department of Obstetrics and Gynecology, ${ }^{2}$ Department of Anasthesia, GMERS Medical College, Valsad, Gujarat,
} India

Received: 07 June 2018

Accepted: 03 July 2018

\section{*Correspondence:}

Dr. Mahesh M. Patel,

E-mail: patelmahesh760@gmail.com

Copyright: ( $)$ the author(s), publisher and licensee Medip Academy. This is an open-access article distributed under the terms of the Creative Commons Attribution Non-Commercial License, which permits unrestricted non-commercial use, distribution, and reproduction in any medium, provided the original work is properly cited.

\begin{abstract}
Background: Unmet need for family planning is an important indicator for assessing the demand for family planning services. As per NFHS-4, the contraceptive prevalence rate in women age 15-49 years was $53.5 \%$ and the unmet need for family planning among married women was $12.9 \%$. Counselling provides the Health care professionals (HCPs) an opportunity to understand the individual need of a contraceptive seeker.

Methods: This was a cross-sectional, observational study conducted at GMERS hospital, Valsad during June 2017 to October 2017. Sexually active women of 18 to 40 years who consulted HCPs for contraception and who interested in starting hormonal contraceptive method or expressed interest in switching (changing) to hormonal methods were included in the study. Total 213 women were enrolled in the study. Questionnaires with information on the women's pre- and post-counseling contraceptive choice, her perceptions, and the reasons behind her post-counseling decision were filled both by the HCP and the participating women. The completed questionnaires were collected and analyzed. Results: During pre-counseling, most common hormonal contraceptive method selected by women was combined hormonal contraceptive pills followed by DMPA, LNG-IUS and POPs. In present study, structured contraception counseling helped most women $(97.2 \%)$ to choose a contraceptive method. There were statistically significant differences in choice of contraceptive methods during pre and post-counseling except COCs. Among hormonal contraceptive methods, maximum difference was observed for choice of the COCs after counseling as compared to pre-counseling. Counseling helped more than $90 \%$ of the women who were indecisive to choose any contraceptive method. More than three fourth of them opted for hormonal methods with a maximum selection of COCs. The most common reasons for selecting COCs was ease of use for COC, breast feeding for POP and the most common reasons for not choosing other available contraceptive methods was discussion with partner.

Conclusions: The combined hormonal contraceptive pills were reported to be the most commonly used contraceptive method. There were statistically significant differences in choice of contraceptive methods during pre and postcounseling with maximum difference in COCs. Counseling helped most of the women who were indecisive to choose any contraceptive method.
\end{abstract}

Keywords: Combined oral contraceptive (COC), Counselling, Health care professionals (HCPs), Progestogen only pill (POP)

\section{INTRODUCTION}

Unmet need for family planning is an important indicator for assessing the demand for family planning services. As per the national family health survey (NFHS-4), the contraceptive prevalence rate in women age 15-49 years was $53.5 \%$ and the unmet need for family planning among married women was $12.9 \%$. The contraceptive usage patterns vary widely in India with prevalence of modern contraception reported to be $47.8 \%$, which 
mainly includes $5.6 \%$ of condoms, $4.1 \%$ of pills, $1.5 \%$ of intrauterine devices (IUD), $0.3 \%$ of male sterilization $36.0 \%$ female sterilization. ${ }^{1}$ This suggests that though a number of contraceptive choices are available, the usage of modern hormonal contraceptive methods is very low. According to NFHS-4, only $53.5 \%$ of current users were informed about side effects of current methods and only $17.7 \%$ of female non-users were ever informed about various family planning methods. ${ }^{1}$ This suggests an unmet need of comprehensive information on contraceptive methods which can be met via counseling in India.

Contraceptive method is determined by a woman's individual needs and preferences. Counselling and information sharing can improve contraceptive compliance, continuation and user satisfaction. By counselling, HCPs can understand the individual need of a contraceptive seeker and provide the information to make an informed decision about contraception. Various studies revealed that structured contraception information and counselling provided by HCPs helped women to select alternative forms of contraception which better corresponded to their lifestyle and needs. ${ }^{2,3}$

This study primarily aimed to evaluate the role of counselling on the decision-making process of various hormonal contraceptive method in Indian women. The study also analyzed socio-demographic predictors of contraceptive choice and comparison of women's precounselling preferences with post-counselling choice.

\section{METHODS}

This was a cross-sectional, observational study conducted at GMERS hospital, Valsad during June 2017 to October 2017. Sexually active women of 18 to 40 years who consulted HCPs for contraception and who interested in starting hormonal contraceptive method or expressed interest in switching (changing) to hormonal methods were included in the study. Total 213 women were enrolled in the study. A structured contraception counselling was formulated. Counselling card for Hormonal Contraceptive methods developed by Federation of Obstetric and Gynecological Societies of India (FOGSI) was used for the study. ${ }^{4}$ Questionnaires with information on the women's pre- and postcounselling contraceptive choice, her perceptions, and the reasons behind her post-counselling decision were filled both by the HCP and the participating women.

After obtaining the informed consent from participating woman, the HCP recorded the method woman intended to use before counselling on Part A1 of the questionnaire. If hormonal contraception was not suitable for the woman then they were excluded from study. Each eligible participating woman was asked to fill Part A2 of the questionnaire which included socio-demographic profile and opinion on various hormonal contraceptive methods like combined oral contraceptive (COC), progestogen only pill (POP), injectable-depot medroxyprogesterone acetate (DMPA), intrauterine system (LNG-IUS), and vaginal ring. HCPs used the comprehensive education material on the available contraceptive methods during counselling. After counselling, woman filled Part B of the questionnaire, which included questions regarding reasons for choosing the contraceptive method and not selecting the other methods. The completed questionnaires were collected and analyzed.

\section{RESULTS}

Two hundred twenty (220) women were screened. Of these, 7 were excluded because of not meeting study eligibility criteria and withdrawal of consent to participate so total of 213 eligible women were included in the final analysis.

Characteristics of women participating in the study are shown in Table 1. Pre-counselling, 96 women (45.1\%) selected hormonal method, $57(26.8 \%)$ non-hormonal method, and 60 (28.2 \%) were undecided for any contraceptive method. After structured contraception counselling, 189 of women $(88.7 \%)$ chose a hormonal contraceptive method.

Table 1: Characteristics of women participating in the study $(n=213)$.

\begin{tabular}{|c|c|c|}
\hline Characteristics & Number $=\mathbf{2 1 3}$ & Percentage \\
\hline \multicolumn{3}{|l|}{ Age groups } \\
\hline $18-20$ & 8 & 3.8 \\
\hline $21-30$ & 134 & 62.9 \\
\hline $31-40$ & 71 & 33.3 \\
\hline \multicolumn{3}{|l|}{ Education } \\
\hline Illiterate & 101 & 47.4 \\
\hline Primary & 64 & 30.0 \\
\hline Secondary & 31 & 14.6 \\
\hline Higher secondary & 12 & 5.6 \\
\hline Graduate and above & 5 & 2.3 \\
\hline \multicolumn{3}{|l|}{ Employment status } \\
\hline Not employed & 132 & 62.0 \\
\hline Employed & 81 & 38.0 \\
\hline \multicolumn{3}{|l|}{ Status of children } \\
\hline 0 & 32 & 15.0 \\
\hline 1 to 2 & 167 & 78.4 \\
\hline 3 to 4 & 12 & 5.6 \\
\hline$\geq 5$ & 2 & 0.9 \\
\hline \multicolumn{3}{|c|}{ Plan to have child later } \\
\hline Yes & 102 & 47.9 \\
\hline No & 74 & 34.7 \\
\hline Don't know yet & 37 & 17.4 \\
\hline \multicolumn{3}{|c|}{ Previous planned pregnancy } \\
\hline Yes & 59 & 27.7 \\
\hline No & 154 & 72.3 \\
\hline
\end{tabular}

Post-counselling, COCs were chosen by $47.9 \%$, injectable-DMPA by $13.6 \%$, LNG-IUS by $16.4 \%$ women, POP by $10.8 \%$ women and other non-hormonal methods 
by $8.5 \%$ women. Around, $2.8 \%$ women remained indecisive about contraceptive method. Maximum difference $(13.1 \%)$ was noted in selection of COCs after counselling as compared to before counselling. Differences in proportions of women who opted for POP, injectable-DMPA, and LNG-IUS post-counselling and pre-counselling were $9.9 \%, 8.5 \%, 12.2 \%$ respectively. These differences were statistically significant except for COCs. Most women $(58,78.3 \%)$ who preferred COCs prior to counselling also opted to use this method after counselling.

Table 2: Cross table for contraceptive method women intended to use before counselling and chosen after counselling.

\begin{tabular}{|llllllll|}
\hline Pre-counseling choice (n) & $\begin{array}{l}\text { Post-counseling choice (n) } \\
\text { COCs }\end{array}$ & $\begin{array}{l}\text { Vaginal } \\
\text { (102) }\end{array}$ & $\begin{array}{l}\text { POPs } \\
\text { ring }(\mathbf{0})\end{array}$ & $\begin{array}{l}\text { (23) } \\
\text { DMPA }\end{array}$ & $\begin{array}{l}\text { LNG- } \\
\text { (29) }\end{array}$ & $\begin{array}{l}\text { Non-hormonal } \\
\text { (35) }\end{array}$ & $\begin{array}{l}\text { Not decided yet } \\
(\mathbf{6})\end{array}$ \\
\hline COCs (74) & 58 & 0 & 4 & 2 & 7 & 2 & 1 \\
\hline Vaginal ring (0) & 0 & 0 & 0 & 0 & 0 & 0 & 0 \\
\hline POPs (2) & 1 & 0 & 1 & 0 & 0 & 0 & 0 \\
\hline DMPA (11) & 6 & 0 & 2 & 3 & 0 & 0 & 0 \\
\hline LNG-IUS (9) & 3 & 0 & 1 & 1 & 4 & 0 & 0 \\
\hline Non-hormonal (57) & 18 & 0 & 7 & 10 & 11 & 11 & 5 \\
\hline Not decided yet (60) & 16 & 0 & 8 & 13 & 13 & 5 & 0 \\
\hline
\end{tabular}

After counselling, total 46 women changed their choice from non-hormonal to hormonal contraceptive method. Out of these 46 women, 18 women $(32.1 \%)$ chose COCs. Therefore, counselling helped women arrive at a decision. After counselling, the highest decrease was observed in the proportion of women indecisive about method to be opted (difference in proportions $=25.4 \%, 54$, $\mathrm{p}$ value $<0.0001)$. Maximum of these women $(16,25.4 \%)$ opted COCs as the post-counselling method of contraception.

Table 3: Post-counselling reasons for selection of contraceptive methods by women.*

\begin{tabular}{|c|c|c|c|}
\hline & Reasons & No. & Percentage \\
\hline \multirow{4}{*}{ COCs (89) } & Easy to use & 48 & 53.9 \\
\hline & $\begin{array}{l}\text { Regular menstrual } \\
\text { bleeding }\end{array}$ & 40 & 44.9 \\
\hline & Daily use & 39 & 43.8 \\
\hline & Less side effects & 20 & 22.5 \\
\hline \multirow{3}{*}{ DMPA (26) } & 3 monthly use & 20 & 76.9 \\
\hline & Easy to remember & 16 & 61.5 \\
\hline & Less side effects & 10 & 38.5 \\
\hline \multirow{3}{*}{$\begin{array}{l}\text { LNG-IUS } \\
(32)\end{array}$} & Long acting & 28 & 87.5 \\
\hline & $\begin{array}{l}\text { Relief from } \\
\text { menstrual bleeding }\end{array}$ & 19 & 59.4 \\
\hline & Less side effects & 15 & 46.9 \\
\hline \multirow{4}{*}{$\begin{array}{l}\text { Progesterone } \\
\text { only Pills } \\
\text { (19) }\end{array}$} & Breast feeding & 16 & 84.2 \\
\hline & Convenience & 12 & 63.2 \\
\hline & Daily use & 11 & 57.9 \\
\hline & Less side effects & 9 & 47.4 \\
\hline
\end{tabular}

*Multiple answers were observed.

Post-counselling reasons for selecting hormonal contraceptive methods are shown in Table 3. Among women who selected COCs, easy to use was the most frequent reason $(48,53.9 \%)$, breast feeding was reported by $16(84.2 \%)$ for POP, long action $(28,87.5 \%)$ for LNG-IUS, 3-monthly use $(20,76.9 \%)$ by who selected injectable-DMPA.

Most frequent reason for non-selection of any contraceptive method was discussion with partner. The most chosen method among women of age groups 21-30 and 31-40 years was COCs. POPs was the second most preferred method among women of age group 21-30 years $(10 \%)$. None of the women in 18-20 years of age group considered Vaginal ring and LNG-IUS.

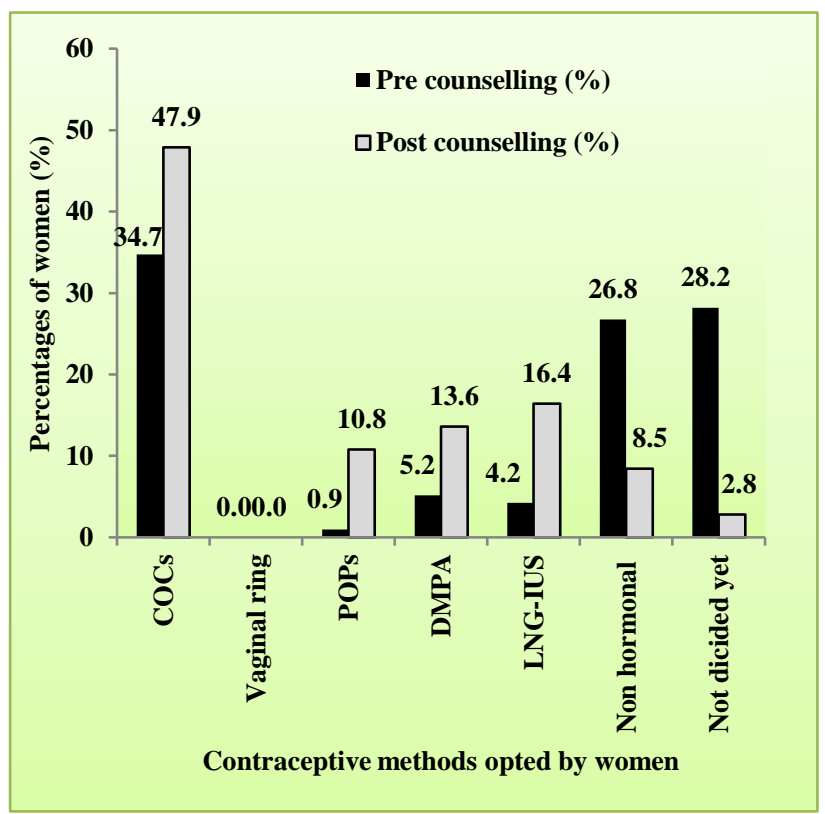

Figure 1: Comparison of contraceptive methods used by women-pre and post-counselling. 


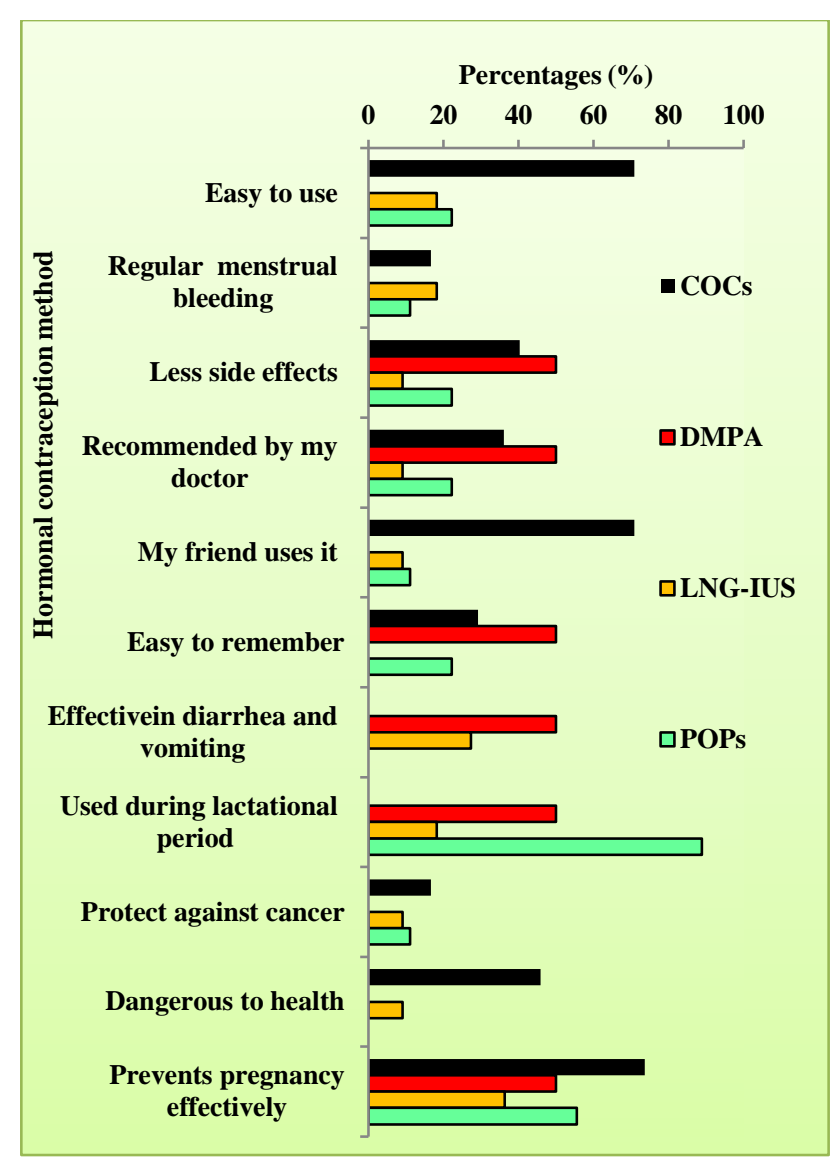

Figure 2: Pre-counselling perceptions of women about contraceptive methods. Percentage of women who agreed with each statement.

\section{DISCUSSION}

Several studies have reported the need and utilization of contraceptives in India. ${ }^{5-7}$ In this study impact of a counseling session by the HCP on contraceptive choices was evaluated. During pre-counseling, most common hormonal contraceptive method selected by women was combined hormonal contraceptive pills followed by DMPA, LNG-IUS and POPs. This is in conformity with the study carried out by Nozer $\mathrm{S}^{4}$

Contraceptive choices were significantly influenced by the counseling sessions provided by HCPs, as evident by the change in proportion of choosing a particular method during pre-counseling versus post-counseling. ${ }^{8}$ In present study, structured contraception counseling helped most women (97.2\%) to choose a contraceptive method. Similar finding was reported in other studies. ${ }^{3,9}$ There was statistically significant differences in choice of contraceptive methods during pre and post-counseling except for COCs. Among hormonal contraceptive methods, maximum difference was observed for choice of the COCs after counseling as compared to precounseling. A significant switch after counseling was observed from non-hormonal methods to hormonal methods of contraception.
Counseling helped more than $90 \%$ of the women who were indecisive to choose any contraceptive method. More than three fourth of them opted for hormonal methods with a maximum selection of COCs. This finding is consistent with results of previous studies. ${ }^{3,10}$

There were different reasons reported by women for selecting a contraceptive method. The most common reasons for selecting COCs was ease of use for $\mathrm{COC}$, breast feeding for POP, long action for LNG-IUS, and 3monthly use for injectable-DMPA and the most common reasons for not choosing other available contraceptive methods was discussion with partner. ${ }^{3,7}$

\section{CONCLUSION}

The combined hormonal contraceptive pills were reported to be the most commonly used contraceptive method. There were statistically significant differences in choice of contraceptive methods during pre and post-counselling with maximum difference in COCs. Counselling helped most of the women who were indecisive to choose any contraceptive method. The Contraceptive choice seemed to be significantly influenced by counselling session.

The limitations were no follow-up visit to assess actual choice of participants; no direct involvement of male partners in counselling and no inclusion of non-hormonal methods in the educational material.

\section{ACKNOWLEDGMENTS}

Authors would like to thank Dr. Pratixa Chaudhari, Associate Professor under whose experienced guidance, this work was conducted and are also thankful to Dr. Vandita K Salat, for their valuable suggestions.

\section{Funding: No funding sources}

Conflict of interest: None declared

Ethical approval: The study was approved by the Institutional Ethics Committee

\section{REFERENCES}

1. International Institute for Population Sciences (IIPS) and ICF. 2017. National Family Health Survey (NFHS-4) fact sheets, 2015-16: India. Mumbai: IIPS. Available http://rchiips.org/NFHS/pdf/NFHS4/India.pdf

2. Bitzer J, Gemzell-Danielsson $\mathrm{K}$, Roumen $\mathrm{F}$, Marintcheva-Petrova M, van Bakel B, Oddens BJ. The CHOICE study: effect of counselling on the selection of combined hormonal contraceptive methods in 11 countries. Eur J Contracept Reprod Health Care. 2012;17:65-78.

3. Lete I, Doval JL, Perez-Campos E, Sánchez-Borrego R, Correa M, de la Viuda E, et al. Factors affecting women's selection of a combined hormonal contraceptive method: the TEAM-06 Spanish crosssectional study. Contraception. 2007;76:77-83. 
4. Sheriar N, Joshi R, Mukherjee B. Impact of counseling on selection of hormonal contraceptive among Indian women. In 18th world congress on controversies in obstetrics, gynecology \& infertility. Vienna, Austria. 2013:24-7.

5. Makade KG, Padhyegurjar M, Padhyegurjar SB, Kulkarni RN. Study of contraceptive use among married women in a slum in Mumbai. Natl J Community Med. 2012;3:40-3.

6. Jain R, Muralidhar S. Contraceptive methods: needs, options and utilization. J Obstet Gynecol India. 2012;61:626-34.

7. Nanda J, Kumar Adak D, Bharati P. Contraceptive practices among adolescent married women in Tamil Nadu, India. Asian Pac J Trop Dis. 2011;1:37-41.

8. United Nations, Department of Economic and Social Affairs, Population Division. 2011. World Contraceptive Use 2010 (POP/ DB/CP/Rev2010). Available http://www.un.org/esa/population/publications/wcu2 010/WCP_2010/Data.html

9. Merckx M, Donders GG, Grandjean P, Van de Sande $\mathrm{T}$, Weyers S. Does structured counselling influence combined hormonal contraceptive choice? Eur J Contracept Reprod Health Care. 2011;16:418-29.

10. Gemzell-Danielsson K, Thunell L, Lindeberg M, Tydén T, Marintcheva-Petrova MA, Oddens BJ. Comprehensive counselling about combined hormonal contraceptives changes the choice of contraceptive methods: results of the CHOICE program in Sweden. Acta Obstet Gynecol Scand. 2011;90:869-77.

Cite this article as: Patel DM, Salat VK, Patel MM. Impact of counselling on selecting a hormonal contraceptive method. Int J Reprod Contracept Obstet Gynecol 2018;7:3325-9. 